DOI: $10.52950 / E S .2021 .10 .2 .007$

\title{
THE OPTIMUM ALLOCATION OF CONSUMPTION OF THE FISHERIAN SHIPWRECKED SAILORS
}

\author{
PAVEL POTUŽÁK
}

\begin{abstract}
:
The theory of interest of Irving Fisher was designed to explain positive, zero, and negative interest rate. One of the intertemporal equilibria with the zero interest is an economy with a given supply of hardtacks for shipwrecked sailors. Hardtacks can be fully saved for the future, but their stock cannot be enlarged by production. Fisher presented several streams of consumption of hardtacks over time. This paper shows that the Fisherian paths are not consistent with the dynamic optimization model. Different trajectories of the optimum consumption are calculated and sketched. Their shape depends on the value of the subjective discount rate, the intertemporal elasticity of substitution in consumption, and the lifetime horizon of the shipwrecked sailors. None of them resemble the original Fisher examples.
\end{abstract}

\section{Keywords:}

Time preference, theory of interest, Fisher

JEL Classification: B25, B53, E43

\section{Authors:}

PAVEL POTUŽÁK, Prague University of Business and Ecoomics, Czech Republic, Email: pavel.potuzak@vse.cz

\section{Citation:}

PAVEL POTUŽÁK (2021). The Optimum Allocation of Consumption of the Fisherian Shipwrecked Sailors. International Journal of Economic Sciences, Vol. X(2), pp. 115-126., 10.52950/ES.2021.10.2.007 


\section{Introduction}

Fisher (1930) presented a general theory of interest that was shaped to explain positive, zero, as well as negative interest rate. The zero interest rate is the intertemporal equilibrium in the economy with fixed endowment of goods that do not depreciate over time and that exhibit zero productivity. Fisher proposed the example of shipwrecked sailors with a given supply of hardtacks.

Mises (1949), Rothbard (1962) and other proponents of the pure time preference theory argued that the interest rate must be always positive because of the existence of the a-priori positive time preference. ${ }^{1}$ Potuzak (2016a, 2016b) argued that the pure time preference theory is a specific case of a more general neoclassical approach, represented also by the Fisherian theory. ${ }^{2}$

Fisher presented possible flows of consumption of hardtacks over time. This paper shows that the paths discussed by Fisher are not accurate. The article depicts trajectories that are consistent with the intertemporal optimization of a representative rational consumer. It is demonstrated that the approach of the pure time preference theory might be incorrect, because the optimum with zero interest and positive time preference does not lead to consumption of all hardtacks in the present period.

\section{Optimum of Shipwrecked Sailors}

In this section, we solve the problem of a Fisherian infinitely and finitely lived shipwrecked sailor who is endowed with a fixed stock of hardtacks $K$. The objective of the sailor is to maximize her lifetime utility function expressed in continuous time as: ${ }^{3}$

$$
U=\int_{0}^{\infty} e^{-\rho \mathrm{t}} u(C(t)) d t
$$

subject to her resource constraint: ${ }^{4}$

$$
\int_{0}^{\infty} C(t) d t \leq K
$$

This condition states that lifetime consumption cannot exceed the initial endowment of hardtacks. Hardtacks have zero productivity, thus the marginal product of capital and the interest rate in this economy is zero. Assuming no satiation point, (2) should be satisfied with equality.

\footnotetext{
1 See also Mises (1940), Block (1978), Garrison (1979), Kirzner (1993), and Herbener (2011).

2 Discussion of the pure time preference theory can be also found in Hayek $(1936,1941,1945)$.

3 This form was first presented in Samuelson (1937). It satisfies all usual neoclassical (and Austrian) assumptions. People prefer present satisfaction to future satisfaction, hence $\rho>0$, which may reflect the second Böhm-Bawerkian (1888) ground for interest. Marginal utility is positive and declines with higher consumption: $u^{\prime}(C)>0$ and u' $(C)<$ 0 for all C. Positive first derivative for all levels of consumption guarantees that more is always preferred to less.

4 See, for example, Strotz (1955:169).
} 
This dynamic problem will be solved with the calculus of variation. ${ }^{5}$ Set up a Lagrangian function:

$$
\int_{0}^{\infty} e^{-\rho \mathrm{t}} u(C(t)) d t+\lambda\left[K-\int_{0}^{\infty} C(t) d t\right]
$$

The solution of this dynamic problem should obey the Euler equation:

$$
\frac{\partial F(\cdot)}{\partial C(t)}=\frac{d \frac{\partial F(\cdot)}{\partial \dot{C}(t)}}{d t}
$$

where $F(\cdot)=e^{-\rho \mathrm{t}} u(C(t))-\lambda C(t) ;$ and $\dot{C}(t)=\frac{d C(t)}{d t}$

Using (4) in solving (3), we get:

$$
e^{-\rho t} u^{\prime}(C(t))-\lambda=0
$$

(5) states that in optimum, the discounted marginal utility of consumption in every period must be identical. To find the optimum growth rate in consumption, we take logarithm of both sides of equation (5):

$$
-\rho t+\ln u^{\prime}(C(t))=\ln \lambda
$$

and differentiate (6) with respect to time:

$$
-\rho+\frac{\frac{d u^{\prime}(C(t))}{d t}}{u^{\prime}(C(t))}=0
$$

Equation (7) reflects the requirement that in the optimum, the growth rate of the marginal utility of consumption must be equal to the subjective discount rate. To achieve this, consumption of hardtacks must be falling over time.

Solving (7), we get:

$$
\frac{u^{\prime \prime}(C(t)) \dot{C}(t)}{u^{\prime}(C(t))}=\rho
$$

(8) might be written as:

5 The presented dynamic optimization methods can be found in Kamien and Schwarz (1991). 


$$
\begin{gathered}
-\frac{\dot{C}(t)}{C(t)} \frac{u^{\prime \prime}(C(t)) C(t)}{u^{\prime}(C(t))}=-\rho \\
\frac{\dot{C}(t)}{C(t)}=\frac{-\rho}{-\frac{u^{\prime \prime}(C(t)) C(t)}{u^{\prime}(C(t))}}
\end{gathered}
$$

Equation (10) describes the optimum growth rate of consumption as a function of the subjective discount rate $\rho$ and the Arrow-Pratt measure of the relative risk aversion $\mathrm{v}(\mathrm{C})$, which is represented by the denominator of $(10)$. For the constant relative risk

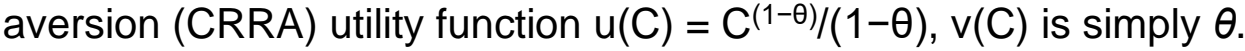

The optimum growth rate of consumption in $(10)$ is $(-\rho / \theta)$ for the CRRA utility function. The optimum consumption path must be decreasing because the interest rate is lower than the subjective discount rate $(0<\rho)$. The shape of this path depends on the size of the relative risk aversion $\theta$.

(7) is a simple differential equation that can be expressed as:

$$
\frac{\mathrm{d} \ln \left[u^{\prime}(C(t))\right]}{d t}=\rho
$$

Its solution is:

$$
u^{\prime}(C(t))=A e^{\rho \mathrm{t}}
$$

$A$ is an arbitrary constant that must be determined. For the CRRA utility function, (12) can be written as:

$$
\begin{aligned}
& C(t)^{-\theta}=A e^{\rho \mathrm{t}} \\
& C(t)=A e^{-\rho t / \theta}
\end{aligned}
$$

At time 0 , the optimum consumption is:

$$
C(0)=A
$$

which must be determined. To do that, insert (14) and (15) into the resource constraint (2): 


$$
\int_{0}^{\infty} C(0) e^{-\rho \mathrm{t} / \theta} d t=K
$$

The solution of $(16)$ is:

$$
\begin{aligned}
& {\left[-C(0) \frac{1}{e^{\rho \mathrm{t} / \theta}} \frac{\theta}{\rho}\right]_{0}^{\infty}=K} \\
& C(0)=K \frac{\rho}{\theta}
\end{aligned}
$$

Because present consumption cannot exceed the initial endowment, $\theta$ must be greater than $\rho$. Substituting (18) into (14) we obtain the optimal consumption path in the infinite horizon:

$$
C(t)=K \frac{\rho}{\theta} e^{-\rho \mathrm{t} / \theta}
$$

To obtain the optimum in the finite horizon, (17) might be written as:

$$
\left[-C(0) \frac{1}{e^{\rho \mathrm{t} / \theta}} \frac{\theta}{\rho}\right]_{0}^{T}=K
$$

Optimal $\mathrm{C}(0)$ is then:

$$
\begin{aligned}
& C(0) \frac{\theta}{\rho}\left(1-\frac{1}{e^{\rho \mathrm{T} / \theta}}\right)=K \\
& C(0)=\frac{\rho}{\theta} \frac{e^{(\rho / \theta) \mathrm{T}}}{e^{(\rho / \theta) \mathrm{T}}-1} K
\end{aligned}
$$

Present consumption must not exceed the initial endowment. (22) thus implies:

$$
\begin{aligned}
& \frac{e^{(\rho / \theta) \mathrm{T}}}{e^{(\rho / \theta) \mathrm{T}}-1} \leq \frac{\theta}{\rho} \\
& \frac{\rho}{\theta} \leq \frac{e^{(\rho / \theta) \mathrm{T}}-1}{e^{(\rho / \theta) \mathrm{T}}} \\
& \frac{\rho}{\theta} \leq 1-\frac{1}{e^{(\rho / \theta) \mathrm{T}}}
\end{aligned}
$$




$$
\begin{aligned}
& \frac{1}{e^{(\rho / \theta) \mathrm{T}}} \leq 1-\frac{\rho}{\theta} \\
& -\frac{\rho}{\theta} T \leq \ln \left(1-\frac{\rho}{\theta}\right)
\end{aligned}
$$

If $\rho / \theta$ is a small number, then:

$$
T \geq 1
$$

If it is not, (27) yields:

$$
\begin{aligned}
& T \geq-\frac{\theta}{\rho} \ln \left(1-\frac{\rho}{\theta}\right) \\
& T \geq \frac{\theta}{\rho} \ln \frac{\theta}{\theta-\rho}
\end{aligned}
$$

$\theta$ must be greater than $\rho$. However, there is also a weak restriction on the length of the planning horizon $T$.

To obtain the optimal path of consumption in the finite horizon $T$, substitute (22) into (14):

$$
\begin{aligned}
& C(t)=\frac{\rho}{\theta} \frac{e^{(\rho / \theta) \mathrm{T}}}{e^{(\rho / \theta) \mathrm{T}}-1} K e^{-\rho \mathrm{t} / \theta} \\
& C(t)=\frac{\rho}{\theta} \frac{e^{\rho(\mathrm{T}-\mathrm{t}) / \theta}}{e^{(\rho / \theta) \mathrm{T}}-1} K
\end{aligned}
$$

\section{Optimum Paths of Consumption}

The simple dynamic model from the previous section can demonstrate that the Fisher predictions about the optimal allocation of hardtacks over time were imprecise. Fisher (1930) concluded that the interest rate in the hard-tack economy must be necessarily zero. However, Fisher (1930, p.188) offered the following figures that display possible optimum consumption paths (Figure 1). 
Figure 1 Optimum paths of consumption of Fisher's shipwrecked sailors in the hardtack economy
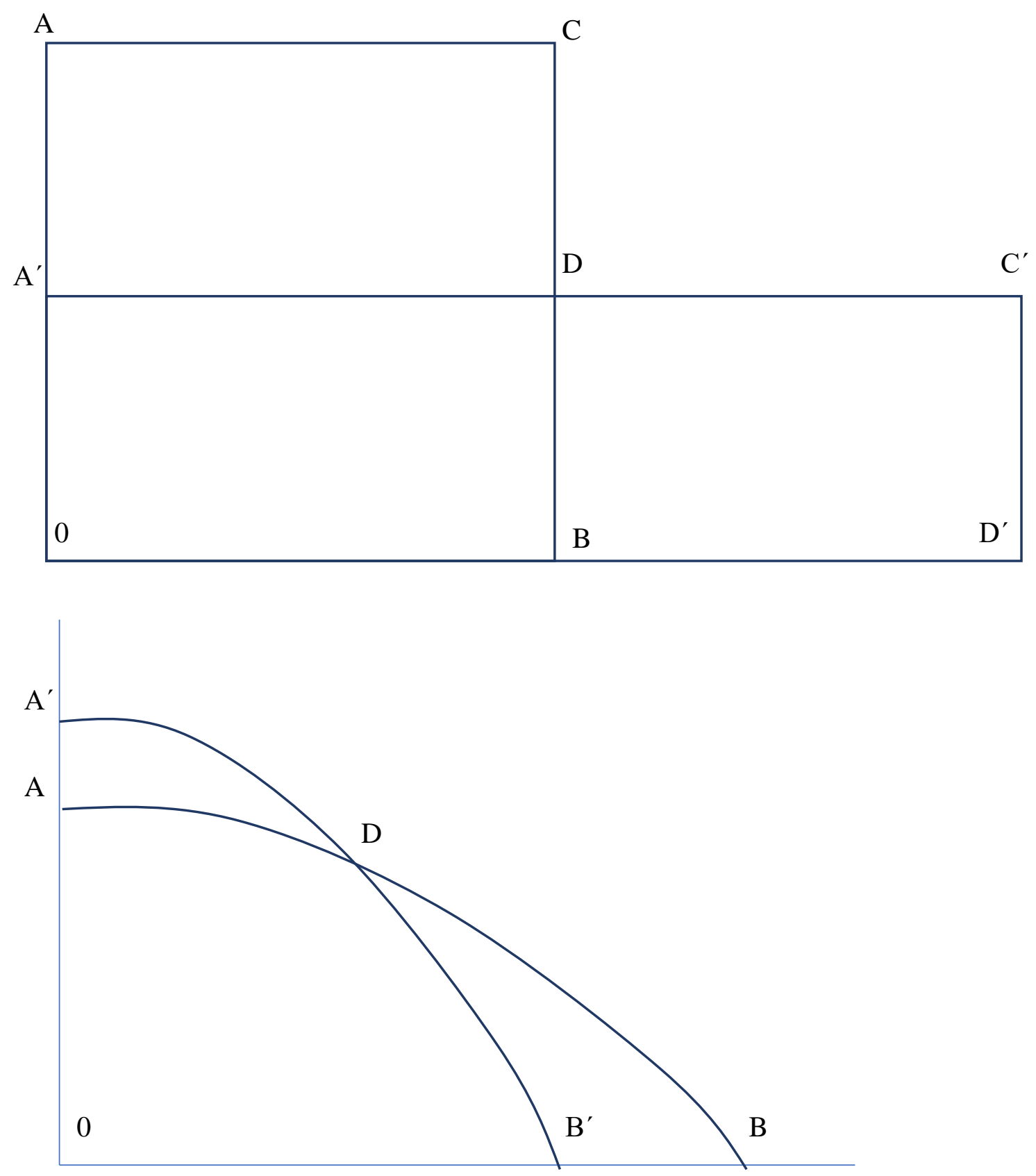

Source: reproduced from Fisher (1930, p. 188).

We demonstrate that none of these paths are optimal. A representative sailor lives for $T$ periods. Her initial endowment of hardtacks is $K$. It cannot be extended by labour effort, by exogenous transfer payments, or by productive investment. The only problem that these sailors face is the optimal allocation of the initial endowment over time. The solution of this problem given in (32).

Figure 2 depicts two optimal paths for different $T$. As can be seen, a longer life requires lower consumption in every period. Figure 3 displays that more patient sailors (lower 
$\rho$ ) have a flatter profile of the optimum consumption. Figure 4 shows that for the given $\rho$, a lower intertemporal elasticity of substitution (higher $\theta$ ) results in a smoother optimum consumption path. ${ }^{6}$ None of these figures resembles the original pictures offered by Fisher. However, he could not have used modern modelling techniques. ${ }^{7}$

Constant consumption of hardtacks over time in not optimal. The reason is the existence of the positive subjective discount rate. Its presence requires that the undiscounted future marginal utility must be higher than the present marginal utility. This can be achieved only with lower consumption in the future. Thus, the preference for present satisfaction over future satisfaction leads to a downward sloping profile of the optimum consumption path.

Although the interest rate is zero, not all hardtacks are consumed in the present period. The reason is the diminishing marginal utility of consumption. This law requires that levels of consumption in two consecutive periods (whose distance is infinitely small in the continuous model) are very close to each other. Hence, we do not observe any dramatic jumps in consumption levels, but a smooth (though decreasing) path.

\section{Figure 2 Optimum path of consumption in a hard-tack economy for different} time horizons. $\theta=1, \rho=0.05, K=10$.

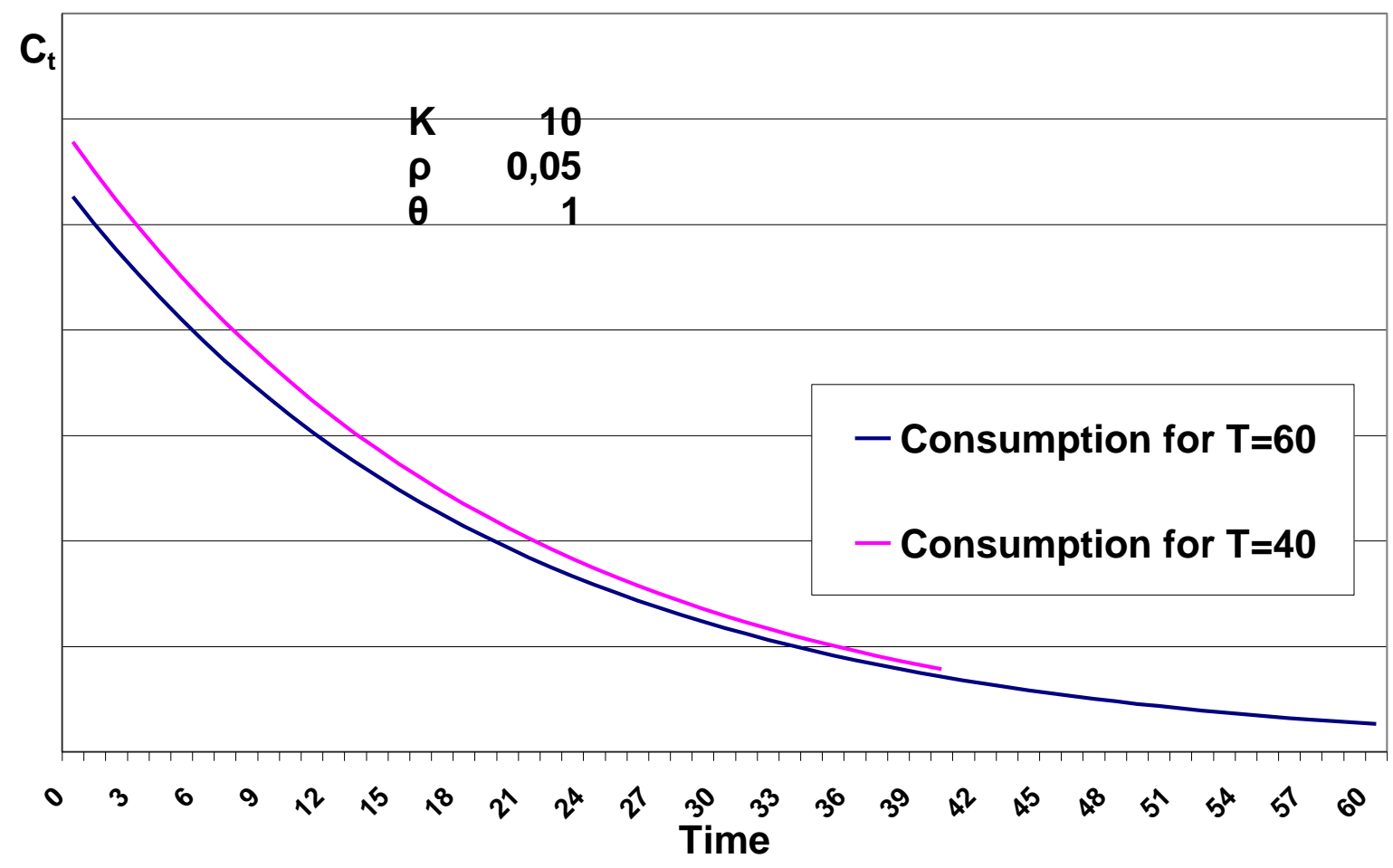

\footnotetext{
${ }^{6}$ As can be seen, $\rho$ and $\theta$ have opposing effects on the optimum consumption path. Higher $\theta$ leads to a smoother profile of consumption, which, however, implies that present consumption is lower. Thus, for a fixed present endowment, higher $\theta$ has similar effects as lower time preference. High preference for consumption smoothing (high $\theta$ ) motivates the consumer to spread her consumption over the entire planning horizon. This leads to a lower present consumption.

7 A similar statement can be found in Woodford $(2003$, p.5) about Wicksell and Hayek when considering their contribution to (modern) monetary theory.
} 
Figure 3 Optimum path of consumption in a hard-tack economy for different subjective discount rates; $\theta=1, T=60$.

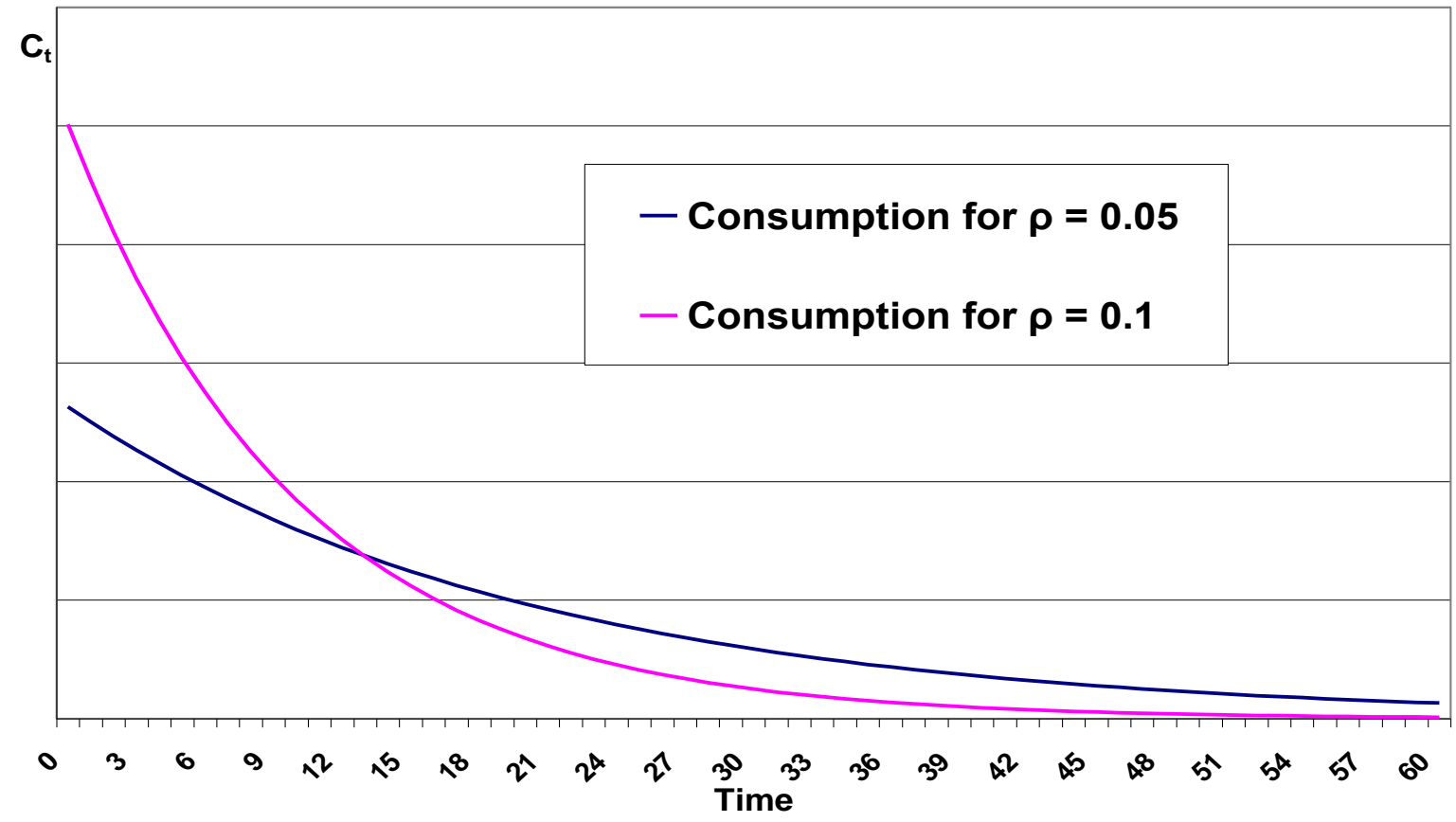

Figure 4 Optimum consumption profile for zero interest rate $(r=0 \%)$ and positive subjective discount rate $(\rho=5 \%), T=60$.

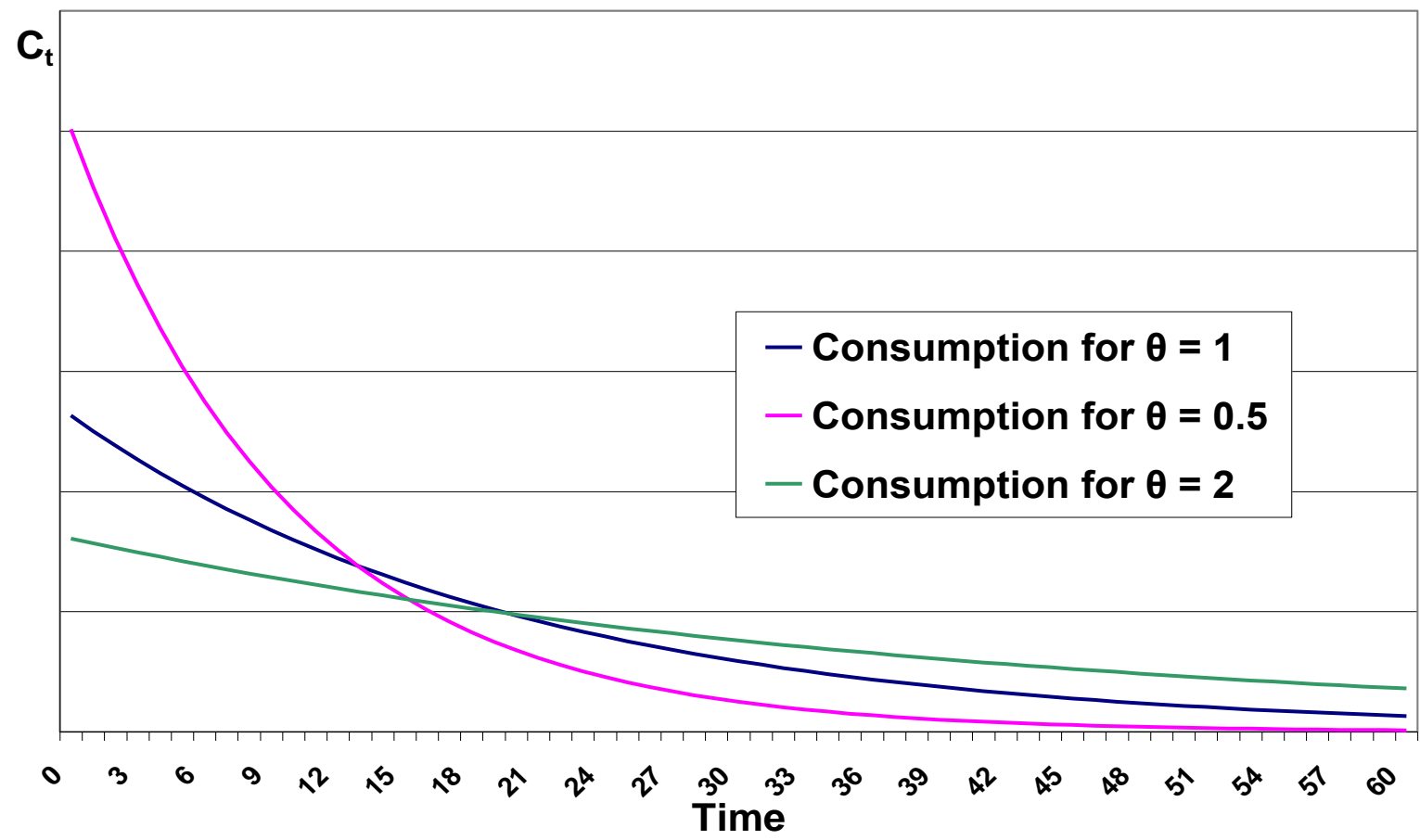


Figure 5 Optimum consumption path if the subsistence level is achieved within the planning horizon.
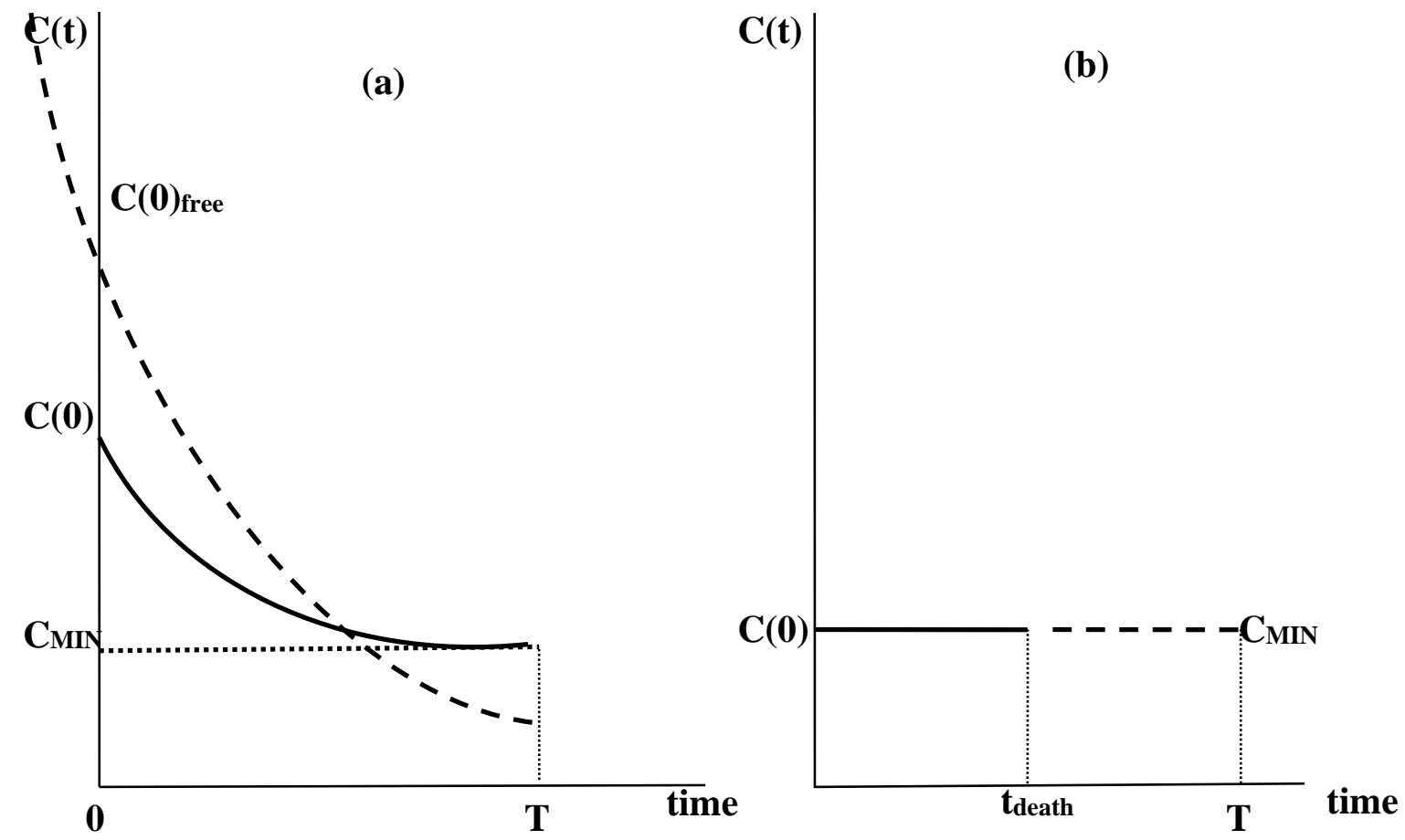

The existence of a positive time preference and a zero rate of interest do not result in a complete exhaustion of resources in the present as the pure time preference theory might argue. The necessary break is performed by the law of diminishing marginal utility. This law is in turn derived from the idea that the given good satisfies wants of lower intensity as its consumption rises in the given period. Hence, it cannot be optimal to move all goods to one period (be it present or future) and leave the needs in the rest of the life unsatisfied. ${ }^{8}$

A more complicated dynamics would be achieved if there was a minimum subsistence level of hardtacks required every period till time $T$. Panel (a) of Figure 5 displays the optimum path of consumption for this possibility, which is also compared with a path at which no subsistence level is required (dashed curve), but which is constrained by the same supply of initial hardtacks. An extreme version, and the most unfortunate, would be if the initial stock was not big enough to preserve life till time $T$ (panel b). However, in this case there are not many economic decisions to analyse.

\section{Concluding Remarks}

The dynamic optimization model shows that the given stock of hardtacks will be allocated differently than the original Fisher approach predicted. The optimum path follows a gradual fall in consumption that is steeper with higher time preference and higher elasticity of intertemporal substitution. The pure time preference theory approach also seems inaccurate. Zero interest rate does not imply consumption of the entire stock in the present period. The reason lies in the effort to ensure a smooth

\footnotetext{
${ }^{8}$ Similar objection along with the presentation of his own position can be found in Knight (1941).
} 
consumption over time, which is a direct consequence of the assumption of diminishing marginal utility of consumption.

A natural extension of this paper is to introduce other forms of productivity proposed by Fisher. Positive constant productivity may generate a positive real rate of interest. It can be shown that zero time preference may co-exist with the positive rate of interest. Yet, not all goods would be postponed to the future, as the pure time preference theory might argue (Potužák 2017; Olson and Bailey, 1981). This situation would be the opposite case discussed in this article.

\section{Acknowledgements}

The author would like to thank anonymous referees for helpful comments and acknowledge the support of grant VSE IGS F5/19/2020 provided by the Prague University of Economics and Business.

\section{References}

Block, Walter. 1978. The Negative Interest Rate: Toward a Taxonomic Critique. Journal of Libertarian Studies 2(2): 121-124.

Böhm-Bawerk, Eugen von. 1891 [1888]. Positive Theory of Capital. New York: G. E. Stechert \& Co.

Fisher, Irving. 1930. Theory of Interest. New York: The Macmillan Company.

Garrison, Roger. 1979. In Defense of the Misesian Theory of Interest. Journal of Libertarian Studies 3(2): 141-150.

Hayek, Friedrich A. von. 1936. Utility Analysis and Interest. The Economic Journal 46(181): 44-60.

Hayek, Friedrich A. von. 1941. The Pure Theory of Capital. Chicago: The University of Chicago Press.

Hayek, Friedrich A. von. 1945. Time-Preference and Productivity: A Reconsideration. Economica 12 (45): $22-25$.

Herbener, Jeffrey M. 2011. Introduction. In The Pure Time-Preference Theory of Interest, ed. Herbener, Jeffrey M., 11-58. Ludwig von Mises Institute

Kamien Morton I., and Schwartz, Nancy L. 1991. Dynamic Optimization: The Calculus Of Variations And Optimal Control in Economics and Management - 2nd ed., NorthHolland, Amsterdam, NY

Knight, Frank H. 1941. Professor Mises and the Theory of Capital. Economica 8(32): 409-427.

Kirzner, Israel. 2011 [1993]. The Pure Time-Preference Theory of Interest: An Attempt at Clarification. In The Pure Time-Preference Theory of Interest, ed. Herbener, Jeffrey M., 99-126. Ludwig von Mises Institute

Mises, Ludwig von. 1974 [1940]. A Critique of Böhm-Bawerk's Reasoning in Support of His Time Preference Theory. In Nationalökonomie. Geneva, Switzerland: Editions Union, 439-44.

Translated from the German by Bettina Bien Greaves and edited by Percy L. Greaves, Jr.

Mises, Ludwig von. 1996 [1949]. Human Action: A Treatise on Economics, 4th ed.

San Francisco: Fox \& Wilkes.

Olson, Mancur and Bailey, Martin J. 1981. Positive Time Preference. Journal of Political Economy 89(1): 1-25.

Potužák, Pavel. 2016a. Fisher and Mises on Zero Interest: A Reconsideration. Prague EconomicPapers, 25(2), 202-220.

Potužák, Pavel. 2016b. Může být přirozená úroková míra nulová? Neoklasický př́stup. (Can the Natural Rate of Interest Be Zero? A Neoclassical Approach.) Politická ekonomie, 64(1), 83-108. 
Potužák, Pavel 2017. Zero time preference and eternal postponement of consumption, Proceedings of Economics and Finance Conferences 4507367, International Institute of Social and Economic Sciences.

Ramsey, Frank P. 1928. A Mathematical Theory of Saving. Economic Journal 38(152): 543-559.

Rothbard, Murray N. 1956. Toward a Reconstruction of Utility and Welfare Economics. In On Freedom and Free Enterprise: Essays in Honor of Ludwig von Mises, ed. Mary Sennholz. 224-262, Princeton, N.J: D. Van Nostrand.

Samuelson. Paul A. 1937. A Note on Measurement of Utility. The Review of Economic Studies 4(2): 155-161.

Strotz. Robert H. 1955. Myopia and Inconsistency in Dynamic Utility Maximization. The Review of Economic Studies 23(3): 165-180.

Woodford, Michael. 2003. Interest and Prices: Foundations of a Theory of Monetary Policy. Princeton University Press. 